\title{
Usefulness of the PERFORM questionnaire to measure fatigue in cancer patients with anemia: a prospective, observational study
}

\author{
Pere Gascón • César A. Rodríguez • Vicente Valentín • \\ Jesús García Mata • Joan Carulla • Javier Cassinello • \\ Ramón Colomer • Eva Baró
}

Received: 28 December 2012 / Accepted: 21 May 2013 /Published online: 22 June 2013

(C) The Author(s) 2013. This article is published with open access at Springerlink.com

\begin{abstract}
Background The PERFORM Questionnaire is a 12-item scale developed for assessing fatigue in cancer patients in the clinical practice. It has advantages over other tools in that it is short and includes beliefs and attitudes of patients about fatigue. It was psychometrically validated in cancer patients with and without anemia.

Purpose We evaluated the usefulness of the PERFORM scale to measure fatigue in a large study focusing exclusively on anemic patients.

Methods This was an observational, multicenter, prospective, 3-month study in cancer patients with hemoglobin $(\mathrm{Hb}) \leq 11 \mathrm{~g} / \mathrm{dl}$. Fatigue was assessed using the PERFORM questionnaire. The overall score ranges from 12 (no fatigue) to 60 (maximum fatigue).

Results We included 667 patients: $54.1 \%$ women, mean age 60 (standard deviation, 12)years. A highly significant, but mild correlation was observed between low baseline $\mathrm{Hb}$ and high
\end{abstract}

P. Gascón

Hospital Clínic de Barcelona, Villarroel 170,

ES-08036 Barcelona, Spain

\section{A. Rodríguez}

Hospital Clínico Universitario de Salamanca, Paseo San Vicente 3,

ES-37007 Salamanca, Spain

\section{Valentín}

Hospital Doce de Octubre, Avda. de Córdoba s/n,

ES-28041 Madrid, Spain

J. G. Mata

Complexo Hospitalario de Ourense, Ramón Puga, 54,

ES-32005 Orense, Spain

J. Carulla

Hospital Vall d'Hebron, Passeig de la Vall d'Hebron, 119,

ES-08035 Barcelona, Spain patient perception of fatigue ( $r$ with PERFORM score $=-0.215$, $p<0.0001)$. Of the patients, $65.8 \%$ improved $\mathrm{Hb}$ level during follow-up (increase of $\geq 1 \mathrm{~g} / \mathrm{dL}$ and/or achieving $>11 \mathrm{~g} / \mathrm{dL}$ ), which translated into a significant improvement in the PERFORM score [mean (95\% confidence interval (CI)] change, $-1.2(-0.04$ to -2.4$)$, whereas more fatigue was observed in patients without improvement in $\mathrm{Hb}$ [change $(95 \% \mathrm{CI})$ in PERFORM, +3.3 (1.5 to 5)]. In a multivariate linear regression analysis, the independent factors associated to fatigue at 3 months were a low $\mathrm{Hb}$ level, a low Karnofsky index, active chemotherapy, cancer treatment with palliative intention, and transfusion need in the last 3 months.

Conclusions Minimal increases or decreases in $\mathrm{Hb}$ of $\geq 1 \mathrm{~g} / \mathrm{dL}$ were associated with meaningful changes in patient-perceived fatigue as measured with the PERFORM questionnaire. In addition to anemia severity, other factors such as active chemotherapy and advanced disease contribute to perception of fatigue by cancer patients.

\section{J. Cassinello}

Hospital Universitario de Guadalajara, Donante de Sangre, 0, ES-19002 Guadalajara, Spain

R. Colomer

Centro Nacional de Investigaciones Oncológicas,

C/ Melchor Fernández Almagro, 3,

ES-28029 Madrid, Spain

E. Baró

3D Health Research, Barcelona, Spain,

Avda Diagonal 472 - 476, Esc. A, 8. ${ }^{\text {a planta, }}$

ES-08006 Barcelona, Spain

P. Gascón $(\bowtie)$

Division of Medical Oncology, Hematology-Oncology

Department, Hospital Clínic de Barcelona, Villarroel 170,

ES-08036 Barcelona, Spain

e-mail: GASCON@clinic.ub.es 
Keywords Fatigue $\cdot$ Anemia $\cdot$ Cancer $\cdot$ Chemotherapy

\section{Introduction}

Fatigue is one of the cancer symptoms with greatest impact in the patients' daily lives, and it is gaining importance as outcome measure [1]. In a recent survey, it was found that $80 \%$ of patients experienced fatigue at least $50 \%$ of the time during treatment, and fatigue was ranked as the symptom most impacting daily life, independently of gender or tumor type [2]. The underlying pathophysiology of cancer-related fatigue is very complex and not completely understood [3]. Although some common mechanisms seem to participate, it is probable that the etiology is not the same in all cancer subpopulations (i.e., patients undergoing active chemotherapy, patients with advanced age, survivors or those with palliative care). It is very important to correctly identify both the biological and psychosocial determinants of fatigue, in order to individualise the therapeutic management.

The etiology of cancer-related fatigue is multifactorial and is related to a variety of factors including chemotherapy with alkylating agents, antimetabolites or platinum compounds, radiotherapy or bone marrow transplantation, changes in blood volume, excess lactate production, hypoglycemia, hypotension, generalized stress responses with or without endocrine dysfunction, sleep disturbances, anxiety, or depression [4-9]. Anemia is one of the factors identified as a causative element in the fatigue experience [10]. Several studies have demonstrated an association between the hemoglobin $(\mathrm{Hb})$ level or its change over time and fatigue intensity assessed by means of Linear Analogue Self-Assessment (LASA) and visual analogue scale (VAS) [11-13]. Furthermore, an association between low hemoglobin and impaired quality of life has also been observed [14].

Anemia is a common complication in cancer patients. According to the European Cancer Anaemia Survey (ECAS), it is present in $72 \%$ of non-solid and $62 \%$ of solid tumor patients [15]. The underlying causes of low $\mathrm{Hb}$ levels include chemotherapy with platinum salts, which affect erythropoietin (EPO) production secondarily to nephrotoxicity [16], direct bone marrow damage, caused by almost all cytotoxic drugs [17-19], or also the underlying malignancy itself, which directly decreases erythropoiesis due to an attenuated endogenous EPO response. Chronic anemia of cancer is also characterized by generalized hypoxia, which results in severe fatigue [20].

Other proposed mechanisms of cancer-related fatigue are a dysregulation of the immune function, a dysfunction of the hypothalamic-pituitary-adrenal axis, altered central nervous system serotonin neurotransmitter activity, vagal afferent signaling, and alterations in muscle metabolism [3]. Several findings support these hypotheses. For example, elevated levels of inflammatory cytokines [21], circulating T lymphocytes [22], increased neutrophil counts [23], and blunted cortisol responses [24, 25] have been found to be associated to fatigue in cancer patients. Other studies have identified associations with sleep disturbances [26-28].

The PERFORM questionnaire is a brief, 12 -items scale which was developed under the auspice of the Spanish Society of Medical Oncology. In the validation study performed in 437 patients with and without anemia, it demonstrated good psychometric properties (overall Cronbach's alpha and intraclass correlation coefficient of 0.94 and 0.83 , respectively; effect size of 0.57 for improved patients and -1 for worsened patients; minimally important difference of 3.5) and accurately reflected improvements in Hb levels [29]. Thus, the PERFORM questionnaire constitutes a good tool to assess perceptions of fatigue of cancer patients in the clinical practice. In order to continue our observations, we have performed a large study focusing exclusively on anemic patients.

The main objective was to prospectively evaluate the association between the $\mathrm{Hb}$ level (and its change over time) and self-perceived fatigue and quality of life in cancer patients with anemia, controlling by possible confounding factors (age, gender, tumor type and stage, cancer treatments, presence of comorbidities such as anxiety, depression, malnutrition, sleep disorders, etc.). All these factors were collected, and its effect on fatigue was evaluated simultaneously with the effect of $\mathrm{Hb}$ level by means of a multivariate analysis, which allowed the estimation of the independent effects. The secondary objectives were to describe anemia management in the clinical practice of Spanish oncology services and to search other clinical, biochemistry, or sociodemographic factors associated to cancer-related fatigue.

\section{Patients and methods}

Study design and population

We performed a prospective, multicenter, observational, 3month study between September 2007 and July 2008 in medical oncology or palliative care departments of 60 Spanish hospitals. The inclusion criteria were: ambulatory patients $\geq 18$ years of age; with a diagnosis of cancer (any site and length of disease duration); with life expectancy of at least 6 months; and with anemia (symptomatic or asymptomatic) defined as $\mathrm{Hb} \leq 11 \mathrm{~g} / \mathrm{dl}$, on inclusion. All eligible subjects who fulfilled the inclusion criteria and provided informed consent were consecutively enrolled in the study. The sample size was calculated based on having $80 \%$ power to detect as significant, at a probability of type I error (alpha) of 0.05 , a correlation coefficient of at least 0.1 between longitudinal changes in PERFORM overall score and $\mathrm{Hb}$ levels. The calculated number of patients required was 660 . The study was approved by the Ethics Committee of the Hospital Clínic in Barcelona and has therefore 
been performed in accordance with the ethical standards laid down in the Declaration of Helsinki.

\section{Variables and procedures}

Sociodemographic and clinical characteristics, and hematology (hemoglobin, hematocrit, leucocyte, lymphocytes, neutrophils, platelets), biochemistry (sodium, potassium, aspartate aminotransferase (AST), alanine aminotransferase (ALT), glucose, albumin, bilirubin, creatinine, lactatedehydrogenase (LDH), serum iron, ferritin, transferrin, vitamin B12, folic acid, endogenous EPO), and fatigue measures were collected at baseline visit and 3 months later. Patient perception of fatigue was assessed using the PERFORM questionnaire and two additional instruments, included as control measures: the LASA scale and a VAS.

The PERFORM Questionnaire (Appendix) is a recently developed questionnaire for assessing patient perception on cancer-related fatigue $[29,30]$. After the generation of a "pool" of 75 candidate items [31], they were administered to a sample of oncology patients in the preliminary assessment study, conducted between January and September 2005 [30]. The psychometric properties of the final, 12-item version were assessed in the validation study, conducted between November 2005 and September 2006, which showed good feasibility, internal consistency, test-retest reliability, convergent validity, and sensitivity to change [29]. The 12 items, whose responses are on a five-point Likert scale, are distributed in three dimensions "Physical Limitations," "Activities of Daily Living," and "Beliefs and Attitudes." An overall score (range from 12 (no fatigue) to 60 (maximum fatigue)) and three dimension subscores (range from 4 to 20) are obtained, with high scores indicating worse patient perception of cancer-related fatigue.

The LASA scale, previously used for assessing healthrelated quality of life in cancer patients $[12,32]$, consists of three items (range for each one from 0 (worse quality of life $(\mathrm{QoL})$ ) to 100 (best QoL)): energy scale, activities of daily living, and overall QoL. Each of them identifies a relevant dimension in the evaluation of quality of life in cancer patients. The LASA scale correlates well with $\mathrm{Hb}$ levels and has shown good reproducibility and sensitivity to change, with minimally important differences of 9.6 for energy level, 8.7 for activities of daily living, and 9.8 for overall QoL [12]. Finally, each patient self-rated fatigue intensity on a 100 -mm horizontal VAS.

\section{Statistical analysis}

Correlations between $\mathrm{Hb}$ level and patient perception of fatigue at baseline, and between changes in $\mathrm{Hb}$ level and changes in fatigue scores during the follow-up were evaluated by using Spearman rank correlation tests. Since the fatigue measures had a normal distribution (confirmed with the Kolmogorov-Smirnov test), changes along time were analyzed using paired $T$ tests in the overall sample and in subgroups of patients defined by an improvement or not in their $\mathrm{Hb}$ level during the study (increase of $\geq 1 \mathrm{~g} / \mathrm{dL}$ or achieving $>11 \mathrm{~g} / \mathrm{dL}$ ). Mean changes and baseline values between subgroups were compared using Mann-Whitney tests or Student's $T$ tests (as applicable). The sensitivity to change was assessed by calculating the effect size (i.e., the standardised mean score change) in the subgroups of patients with and without improvement in $\mathrm{Hb}$ levels. Changes in hematology and serum biochemistry parameters between baseline and 3-month visits were evaluated using paired $T$ tests.

Bivariate associations between patients' characteristics (sociodemographic and clinical variables, hematology and biochemistry values) and fatigue measures were assessed using Student's $T$ tests or analysis of variance. Effect measures were expressed as difference in means together with the $95 \%$ confidence interval with respect to the reference category (the one with less fatigue). A multivariate linear regression model was built to identify the independent factors associated to perception of fatigue (overall PERFORM score) at 3 months. Statistical analyses were performed with the $\mathrm{SAS}^{\circledR}$ package version 8.2. (SAS Institute, Cary, NC, USA).

\section{Results}

Demographic and clinical characteristics

The study included 667 cancer patients with anemia. The main characteristics of the study population are shown in Table 1.

Hematology and serum biochemistry parameters where mostly within normal limits (Table 2), both at baseline and 3-month visit, with the exception of: low hematocrit and $\mathrm{Hb}$ levels (as defined by protocol), and elevated mean LDH and endogenous EPO levels. Ferritin levels were in the upper limit of normality. During the prospective follow-up, the $\mathrm{Hb}$ $(p<0.001)$, hematocrit $(p<0.001)$, serum iron $(p=0.026)$, AST $(p=0.002)$, and albumin levels $(p<0.001)$ displayed a significant increase, whereas the platelet count $(p<0.001)$ and the glucose levels $(p=0.007)$ decreased (Table 2$)$.

Evolution and management of anemia

At baseline, $65.1,33.3$, and $1.6 \%$ of patients had mild ( $>10$ to $\leq 11 \mathrm{~g} / \mathrm{dL}$ ), moderate ( $\geq 8$ to $\leq 10 \mathrm{~g} / \mathrm{dL}$ ), and severe anemia $(<8 \mathrm{~g} / \mathrm{dL}$ ), respectively (Table 3$)$. At 3 months, the percentage of anemic patients had decreased to $43.3 \%$, and $65.8 \%$ of patients had an improvement in their $\mathrm{Hb}$ level (defined as increase of $\geq 1 \mathrm{~g} / \mathrm{dL}$ or achieving $>11 \mathrm{~g} / \mathrm{dL}$ ). The severity of anemia in the subgroup of patients who remained with $\mathrm{Hb}$ $<11 \mathrm{~g} / \mathrm{dL}$ was similar than at baseline (Table 3). 
Table 1 Demographic and clinical characteristics of the study population at baseline and 3-month visits $(N=667)$

\begin{tabular}{|c|c|c|c|c|}
\hline & $\begin{array}{l}\text { Valid } \\
N^{\mathrm{a}}\end{array}$ & $\begin{array}{l}\text { Baseline } \\
\text { visit }\end{array}$ & $\begin{array}{l}\text { Valid } \\
N^{\mathrm{a}}\end{array}$ & $\begin{array}{l}\text { 3-month } \\
\text { visit }\end{array}$ \\
\hline Gender, $N(\%)$ & 667 & & & \\
\hline Men & & $306(45.9)$ & & - \\
\hline Women & & $361(54.1)$ & & - \\
\hline Age (years) & 667 & & & \\
\hline Mean (SD) & & $59.9(12.1)$ & & - \\
\hline Range & & [20-89] & & - \\
\hline Cancer type ${ }^{\mathrm{b}}, N(\%)$ & 667 & & & \\
\hline Breast & & $129(19.3)$ & & - \\
\hline Lung & & $133(19.9)$ & & - \\
\hline Ovarian & & $52(7.8)$ & & - \\
\hline Head and neck & & $33(5.0)$ & & - \\
\hline Genitourinary & & $49(7.3)$ & & - \\
\hline Gastrointestinal & & $194(29.1)$ & & - \\
\hline Lymphoma & & $16(2.4)$ & & - \\
\hline Other & & $117(17.5)$ & & - \\
\hline Time since diagnosis (years) & 657 & & & \\
\hline Mean (SD) & & $2.1(3.1)$ & & - \\
\hline Range & & {$[0-27.4]$} & & - \\
\hline Family situation, $N(\%)$ & 665 & & & \\
\hline $\begin{array}{l}\text { Patient does not need care from } \\
\text { another person }\end{array}$ & & $450(67.7)$ & & - \\
\hline $\begin{array}{l}\text { Patient needs and receives care } \\
\text { from a relative, a caregiver } \\
\text { or both }\end{array}$ & & $215(32.3)$ & & - \\
\hline Spread of cancer, $N(\%)$ & 666 & & 537 & \\
\hline Local & & $123(18.5)$ & & $113(21.0)$ \\
\hline Locoregional & & $163(24.4)$ & & $111(20.7)$ \\
\hline Metastatic & & $380(57.1)$ & & $313(58.3)$ \\
\hline Karnofsky index (\%) & 651 & & & \\
\hline Mean (SD) & & $81.8(12.1)$ & & - \\
\hline Range & & [1-100] & & - \\
\hline Cancer treatment, $N(\%)$ & 667 & & 541 & \\
\hline Without treatment & & $62(9.3)$ & & $176(32.5)$ \\
\hline In treatment ${ }^{\mathrm{b}}$ & & $605(90.7)$ & & $365(67.5)$ \\
\hline Chemotherapy & & $553(82.9)$ & & $220(40.7)$ \\
\hline Monoclonal antibodies & & $43(6.4)$ & & $35(6.5)$ \\
\hline Radiotherapy & & $48(7.2)$ & & $23(4.3)$ \\
\hline Hormone therapy & & $20(3.0)$ & & $28(5.2)$ \\
\hline Interferon & & $1(0.1)$ & & $1(0.2)$ \\
\hline Symptomatic treatment & & $70(10.5)$ & & $54(10.0)$ \\
\hline Pain & & $51(7.6)$ & & $36(6.7)$ \\
\hline Other & & $28(4.2)$ & & $34(6.3)$ \\
\hline Treatment intention & 602 & & 365 & \\
\hline Adjuvant & & $111(18.4)$ & & $57(15.6)$ \\
\hline Curative & & $83(13.8)$ & & $38(10.4)$ \\
\hline Palliative & & $408(67.8)$ & & $270(74.0)$ \\
\hline Comorbidities $^{\mathrm{b}}$ & 667 & & & \\
\hline Anxiety & & $75(11.2)$ & & $62(11.5)$ \\
\hline
\end{tabular}

Table 1 (continued)

\begin{tabular}{|c|c|c|c|c|}
\hline & $\begin{array}{l}\text { Valid } \\
N^{\mathrm{a}}\end{array}$ & $\begin{array}{l}\text { Baseline } \\
\text { visit }\end{array}$ & $\begin{array}{l}\text { Valid } \\
N^{\mathrm{a}}\end{array}$ & $\begin{array}{l}3 \text {-month } \\
\text { visit }\end{array}$ \\
\hline Depression & & $65(9.7)$ & & $58(10.7)$ \\
\hline Dehydration & & $4(0.6)$ & & $4(0.7)$ \\
\hline Infection & & $8(1.2)$ & & $7(1.3)$ \\
\hline Heart failure & & $10(1.5)$ & & $13(2.4)$ \\
\hline Respiratory failure & & $42(6.3)$ & & $32(5.9)$ \\
\hline Chronic kidney disease & & $14(2.1)$ & & $10(1.8)$ \\
\hline Liver disease & & $14(2.1)$ & & $13(2.4)$ \\
\hline Malnutrition & & $12(1.8)$ & & $25(4.6)$ \\
\hline Diarrhoea & & $5(0.75)$ & & $2(0.4)$ \\
\hline Sleep disorders & & $24(3.6)$ & & $17(3.1)$ \\
\hline
\end{tabular}

$S D$ standard deviation

${ }^{a}$ There were missing values in the data set

${ }^{\mathrm{b}}$ Each patient could have more than one response

Only $42.4 \%$ of patients received treatment for anemia at baseline visit, mainly erythropoiesis-stimulating agents (ESAs) and/or supplements (87\% iron supplementation; Table 3). At 3-month visit, the percentage of patients with treatment for anemia had increased to $55.8 \%(p<0.001)$, but the relative distribution of the different treatments was similar (Table 3).

Patients treated with transfusions alone or in combination had lower mean baseline Hb level (9.1 (standard deviation (SD), 1.0) g/dL) than any other group (10.0 $(\mathrm{SD}, 0.7) \mathrm{g} / \mathrm{dL}$ in patients with ESA alone, 9.8 (SD, 0.7) $\mathrm{g} / \mathrm{dL}$ in patients with ESA and supplements, 10.2 (SD, $0.7) \mathrm{g} / \mathrm{dL}$ in patients with supplements alone, and 10.3 $(\mathrm{SD}, 0.6) \mathrm{g} / \mathrm{dL}$ in patients without treatment, $p<0.0001$ between groups). Mean change in $\mathrm{Hb}$ during the followup was similar in all these subgroups $(p=0.511$, data not shown).

Fatigue measures and correlation with $\mathrm{Hb}$

Table 3 displays mean fatigue scores at baseline and 3-month visits in the overall group for the three administered instruments. At baseline, both the PERFORM questionnaire and the two control measures (LASA and VAS) reflected an impairment of medium-degree intensity. Mean PERFORM overall score at baseline in patients with mild, moderate, and severe anemia was 31.6 (SD, 12.5), 36.6 (SD, 13.9), and 41.6 (SD, $11.9)$, respectively.

At 3 months, a significant improvement in fatigue was observed as measured by the "Beliefs and attitudes" dimension of the PERFORM questionnaire $(p=0.036)$ and by the three LASA subcales $(p=0.006,0.003$, and 0.004 , respectively; Table 3). 
Table 2 Hematology and serum biochemistry parameters in the study population at baseline and 3-month visits
$A L T$ alanine aminotransferase, $A S T$ aspartate aminotransferase, $E P O$ epoetin, $L D H$ lactatedehydrogenase

${ }^{a}$ There were missing values in the data set

\begin{tabular}{|c|c|c|c|c|c|}
\hline & \multicolumn{2}{|c|}{ Baseline visit } & \multicolumn{2}{|c|}{ 3-month visit } & \multirow[t]{2}{*}{$P$ value } \\
\hline & Valid $N^{\mathrm{a}}$ & Mean (SD) & Valid $N^{\mathrm{a}}$ & Mean (SD) & \\
\hline Hemoglobin (g/dL) & 667 & $10.1(0.8)$ & 527 & $11.2(1.5)$ & $<0.001$ \\
\hline Hematocrit (\%) & 650 & $30.5(2.7)$ & 519 & $33.6(4.5)$ & $<0.001$ \\
\hline Leucocyte $\left(10^{3} / \mathrm{mm}^{3}\right)$ & 654 & $6.3(3.6)$ & 522 & $6.3(3.4)$ & 0.666 \\
\hline Lymphocytes $\left(10^{3} / \mathrm{mm}^{3}\right)$ & 386 & $1.4(0.7)$ & 280 & $1.4(0.7)$ & 0.706 \\
\hline Neutrophils $\left(10^{3} / \mathrm{mm}^{3}\right)$ & 389 & $3.9(2.5)$ & 278 & $3.8(2.1)$ & 0.716 \\
\hline Platelets $\left(10^{3} / \mathrm{mm}^{3}\right)$ & 637 & $282.2(133.2)$ & 519 & $247.7(111)$ & $<0.001$ \\
\hline Sodium $(\mathrm{mEq} / \mathrm{L})$ & 474 & $139.2(3.2)$ & 414 & $139.5(3.4)$ & 0.133 \\
\hline Potassium (mEq/L) & 466 & $4.3(0.5)$ & 403 & $4.3(0.5)$ & 0.326 \\
\hline AST (U/L) & 395 & $25.9(23.8)$ & 348 & $32.5(31.8)$ & 0.002 \\
\hline ALT (U/L) & 408 & $28.2(22.9)$ & 356 & $29.5(22.7)$ & 0.243 \\
\hline Glucose (mmol/L) & 486 & $5.9(1.9)$ & 421 & $5.7(1.7)$ & 0.007 \\
\hline Albumin (g/dL) & 254 & $3.8(0.6)$ & 250 & $3.9(0.6)$ & $<0.001$ \\
\hline Bilirubin (mg/dL) & 410 & $0.5(0.4)$ & 357 & $0.6(0.3)$ & 0.164 \\
\hline Creatinine (mg/dL) & 550 & $0.9(0.4)$ & 470 & $0.9(0.4)$ & 0.380 \\
\hline LDH (U/L) & 300 & $424.8(242.9)$ & 276 & $404.3(222)$ & 0.329 \\
\hline Serum iron $(\mu \mathrm{g} / \mathrm{dL})$ & 78 & $51.2(33.5)$ & 71 & $58.9(28.5)$ & 0.026 \\
\hline Ferritin (ng/dL) & 48 & $300.3(316.4)$ & 49 & $275.8(291.2)$ & 0.652 \\
\hline Transferrin (\%) & 37 & $18(7.5)$ & 41 & $17.8(8.8)$ & 0.837 \\
\hline Vitamin B12 (pg/mL) & 40 & $582.9(501.4)$ & 45 & $592.1(400.1)$ & 0.400 \\
\hline Folic acid (ng/mL) & 39 & $9.2(6)$ & 34 & $10.3(6.2)$ & 0.518 \\
\hline Endogenous EPO (IU/L) & 4 & $56.7(39.9)$ & 7 & $50.8(30.5)$ & 0.777 \\
\hline
\end{tabular}

At baseline, the correlations between fatigue measures and $\mathrm{Hb}$ level were statistically significant in all cases, and showed relationships of moderate degree $(r=-0.215,-0.187,-0.221$, $-0.164, p<0.001$ in all cases, for the PERFORM overall, activities of daily living, beliefs and attitudes, and physical limitations scores; $r=-0.134, p<0.001$ for the VAS score; and $r=0.108, p=0.005, r=0.099, p=0.01$ and $r=0.103, p=0.007$ for the energy, activities of daily living, and overall QoL LASA subscales, respectively; Table 4).

At 3 months, the correlation coefficient between $\mathrm{Hb}$ level and PERFORM overall score was similar than at baseline visit $(r=-0.249, p<0.0001)$. A significant negative correlation was also observed between 3-month changes in $\mathrm{Hb}$ level and 3 -month changes in PERFORM score $(r=-0.255, p<0.0001)$.

Fatigue in subgroups with and without improvement in $\mathrm{Hb}$

Table 5 shows 3-month changes in fatigue scores in patients with and without improvement in $\mathrm{Hb}$ level. At baseline, no significant differences were observed between these two groups.

During the follow-up, mean changes in fatigue scores were significantly different for the three questionnaires, resulting in effect sizes ranging from 0.07 to 0.20 (absolute values) in improved patients, and from 0.12 to 0.32 in nonimproved patients (Table 5).
Factors associated to fatigue

At baseline visit, factors associated to fatigue as measured by overall PERFORM score were: Hb level $(r=-0.215$, $p<0.0001)$, low Karnofsky score $(r=-0.275, p<0.0001)$, high ferritin levels $(r=0.338, p=0.040)$, need for caregiver (difference in mean versus patients who do not need care, +8.7 , $p<0.0001)$, treatment with palliative intention $(+5.2$ versus treatment with curative intention, $p=0.001)$, and metastatic tumor $(+4.3$ versus local tumor, $p=0.018)$. No relationship was found with age, gender, educational level, serum iron, transferrin saturation, time since diagnosis, tumor location or active cancer treatment (data not shown).

At 3 months, factors associated to fatigue were: longer time since diagnosis, lower Karnofsky index, lower $\mathrm{Hb}$ at baseline and at 3 months, lower change in $\mathrm{Hb}$ during the follow-up, lower serum iron at baseline, lung cancer type, metastatic tumor, active cancer treatment, chemotherapy administration, palliative cancer treatment intention, heart and/or respiratory failure, administration of ESA, and transfusion use (Table 6).

After multivariate adjustment, the independent factors that remained associated to fatigue (global PERFORM score) at 3 months were: a low $\mathrm{Hb}$ level (coefficient $\beta+1.43(+0.60$ to +2.26 ) for each $-1 \mathrm{~g} / \mathrm{dL}, p=0.001$ ), a low Karnofsky index 
Table 3 Description of anemia degree, treatments for anemia, and patient-perception of fatigue in the study population at baseline and 3-month visits

\begin{tabular}{|c|c|c|c|c|c|}
\hline & Valid $N^{\mathrm{a}}$ & Baseline visit & Valid $N^{\mathrm{a}}$ & 3-month visit & $P$ value \\
\hline Anemia degree $(\mathrm{g} / \mathrm{dL})$ & 667 & & 527 & & $<0.001$ \\
\hline No anemia $(>11 \mathrm{~g} / \mathrm{dL})$ & & 0 & & $299(56.7)$ & \\
\hline Mild anemia $(>10$ to $\leq 11 \mathrm{~g} / \mathrm{dL})$ & & $434(65.1)$ & & $128(24.3)$ & \\
\hline Moderate anemia ( $\geq 8$ to $\leq 10 \mathrm{~g} / \mathrm{dL}$ ) & & $222(33.3)$ & & $87(16.5)$ & \\
\hline Severe anemia $(<8 \mathrm{~g} / \mathrm{dL})$ & & $11(1.6)$ & & $13(2.5)$ & \\
\hline Type of treatment for anemia, $N(\%)$ & 667 & & 541 & & $<0.001$ \\
\hline None & & $384(57.6)$ & & $239(44.2)$ & \\
\hline Only transfusions & & $32(4.8)$ & & $36(6.6)$ & \\
\hline Only supplements & & $69(10.3)$ & & $67(12.4)$ & \\
\hline Only ESA & & $90(13.5)$ & & $80(14.8)$ & \\
\hline Transfusions + supplements & & $12(1.8)$ & & $11(2)$ & \\
\hline Transfusion + ESA & & $20(3)$ & & $29(5.4)$ & \\
\hline ESA+supplements & & $47(7)$ & & $56(10.3)$ & \\
\hline Transfusion+ESA+supplements & & $13(1.9)$ & & $23(4.3)$ & \\
\hline \multicolumn{6}{|l|}{ PERFORM questionnaire, mean (SD) } \\
\hline Global score & 542 & $33.4(13.2)$ & 427 & $31.9(13.3)$ & 0.051 \\
\hline Activities of daily living & 618 & $11.1(4.3)$ & 483 & $10.7(4.4)$ & 0.140 \\
\hline Beliefs and attitudes & 584 & $11.4(4.7)$ & 461 & $10.8(4.7)$ & 0.036 \\
\hline Physical limitations & 633 & $11.0(5.0)$ & 500 & $10.5(5.0)$ & 0.106 \\
\hline VAS fatigue $(\mathrm{mm})$, mean $(\mathrm{SD})$ & 652 & $45.5(27.6)$ & 510 & $46.4(28.8)$ & 0.597 \\
\hline \multicolumn{6}{|l|}{ LASA (mm), mean (SD) } \\
\hline Energy & 656 & $52.3(23.7)$ & 512 & $56.0(24.5)$ & 0.006 \\
\hline Activities of daily living & 652 & $53.6(27.2)$ & 512 & $58.1(26.6)$ & 0.003 \\
\hline Overall quality of life & 656 & $56.1(23.7)$ & 514 & $59.7(24.5)$ & 0.004 \\
\hline
\end{tabular}

Each patient could have more than one response; supplements include: iron, B12 vitamin, folic acid

ESA erythropoiesis-stimulating agents, LASA Linear Analogue Self-Assessment, SD standard deviation, VAS Visual Analogue Scale

${ }^{\mathrm{a}}$ There were missing values in the data set

Table 4 Correlation between hemoglobin level and patient-perception of fatigue at baseline visit $(N=667)$

\begin{tabular}{llll}
\hline $\begin{array}{l}\text { Baseline fatigue } \\
\text { evaluations }\end{array}$ & \multicolumn{3}{l}{ Baseline hemoglobin level } \\
\cline { 2 - 4 } & $N^{\mathrm{a}}$ & $\begin{array}{l}\text { Correlation } \\
\text { coefficient }^{\mathrm{b}}\end{array}$ & $P$ value \\
\hline PERFORM questionnaire & 542 & -0.215 & $<0.001$ \\
Global score & 618 & -0.187 & $<0.001$ \\
Activities of daily living & 584 & -0.221 & $<0.001$ \\
Beliefs and attitudes & 633 & -0.164 & $<0.001$ \\
Physical limitations & 652 & -0.134 & $<0.001$ \\
VAS fatigue & & & \\
LASA & 656 & 0.108 & 0.005 \\
Energy & 652 & 0.099 & 0.010 \\
Activities of daily living & 656 & 0.103 & 0.007 \\
Overall quality of life & & & \\
\hline
\end{tabular}

LASA Linear Analogue Self-Assessment, VAS Visual Analogue Scale

${ }^{a}$ There were missing values in the data set

${ }^{\mathrm{b}}$ Rho Spearman (coefficient $\beta+0.19(+0.08$ to +0.29$)$ for each $+1 \%$, $p<0.0001)$, active chemotherapy (coefficient $\beta 5.07(+1.81$ to +8.32$), p=0.002)$, cancer treatment with palliative intention (coefficient $\beta+2.97(+0.33$ to +5.61$), p=0.028)$, and transfusion need in the last 3 months (coefficient $\beta+4.66(+0.34$ to + $8.98), p=0.035$ ).

\section{Discussion}

The PERFORM questionnaire is a brief, recently validated scale, specifically developed in the Spanish cultural environment, for the assessment of perceptions and beliefs about cancer-related fatigue, which has demonstrated excellent psychometric properties [30]. The present study constitutes the first use of this 12-item tool in the routine management of Spanish cancer patients.

At baseline, we administered the PERFORM questionnaire to a cohort characterized by low $\mathrm{Hb}$ levels, with the aim to describe the relationship between anemia and perception of fatigue by patients. The significant correlation found between 


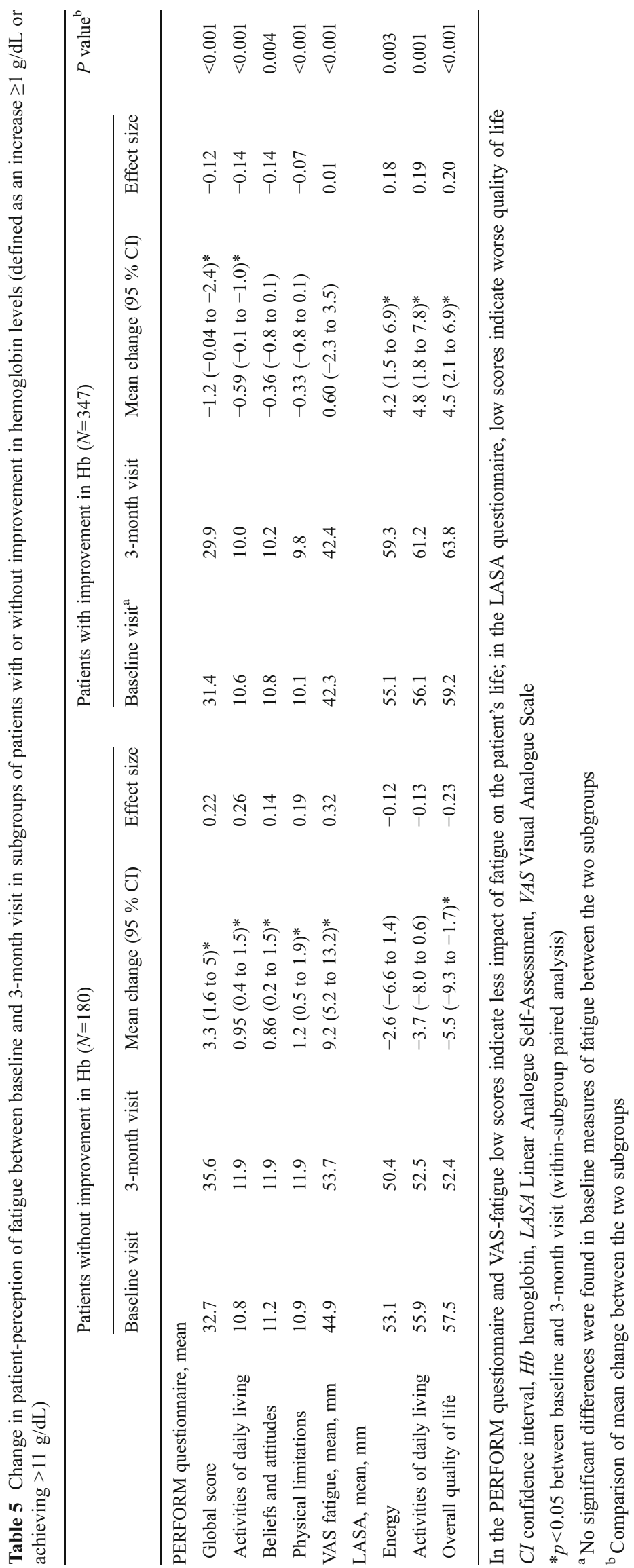


Table 6 Association between clinical and sociodemographic characteristics of cancer patients and perception of fatigue at 3-month visit (PERFORM questionnaire, overall score)
No significant association was observed between overall PERFORM score and the following variables: age, gender, ferritin levels, transferrin saturation, radiotherapy, hormone therapy, monoclonal antibodies, interferon, symptomatic treatment, supplements, chronic kidney disease, anxiety and/or depression, dehydration and/or malnutrition and/or diarrhea, infection, liver disease, sleep disorders

CI confidence interval, ESA erythropoiesis-stimulating agent

\begin{tabular}{|c|c|c|}
\hline & PERFORM score at 3 months & \\
\hline Continuous variables & Coefficient of correlation & $P$ value \\
\hline Time since diagnosis & 0.099 & 0.042 \\
\hline Karnofsky index & -0.199 & $<0.0001$ \\
\hline Hemoglobin at baseline & -0.115 & 0.017 \\
\hline Hemoglobin at 3 months & -0.249 & $<0.0001$ \\
\hline Change in hemoglobin & -0.196 & $<0.0001$ \\
\hline Serum iron at baseline & -0.307 & 0.048 \\
\hline Categorical variables & Difference in mean PERFORM score $(95 \% \mathrm{CI})$ & $P$ value \\
\hline Cancer type & & 0.012 \\
\hline Lung & $+4.5(+7.9$ to +1.0$)$ & \\
\hline Other & Reference & \\
\hline Spread of cancer, $N(\%)$ & & 0.002 \\
\hline Local & Reference & \\
\hline Locoregional & $+0.9(-2.6$ to +4.3$)$ & \\
\hline Metastatic & $+5.4(+2.2$ to +8.5$)$ & \\
\hline Cancer treatment & & 0.002 \\
\hline Without treatment & Reference & \\
\hline In treatment & $+7.0(+3.8$ to +10.2$)$ & \\
\hline Type of cancer treatment & & $<0.0001$ \\
\hline Chemotherapy & $+5.9(+3.0$ to +8.8$)$ & \\
\hline Without chemotherapy & Reference & \\
\hline Cancer treatment intention & & $<0.0001$ \\
\hline Palliative & $+6.3(+3.9$ to +8.7$)$ & \\
\hline Adjuvant or curative & Reference & \\
\hline Comorbidities & & 0.030 \\
\hline Heart and/or respiratory failure & $+5.3(+0.6$ to +10.0$)$ & \\
\hline Without heart and/or respiratory failure & Reference & \\
\hline Type of treatment for anemia & & 0.006 \\
\hline Transfusions & $+6.3(+2.0$ to +10.7$)$ & \\
\hline Without transfusions & Reference & \\
\hline Type of treatment for anemia & & 0.001 \\
\hline ESA & $+5.0(+2.1$ to +7.9$)$ & \\
\hline Without ESA & Reference & \\
\hline
\end{tabular}

the $\mathrm{Hb}$ level and the three fatigue measures (the PERFORM questionnaire and the two control measures LASA and VAS), ranging between 0.10 and 0.22 , is in line with what has been published so far in the literature [12]. During the follow-up, approximately $50 \%$ of patients had their anemia corrected, and the PERFORM questionnaire was able to capture an improvement in fatigue perception, whereas the LASA scale did not show a significant change. In patients without $\mathrm{Hb}$ improvement, an overall worsening of fatigue and QoL was observed, suggesting that patient's overall status had deteriorated due to cancer progression. In the multivariate analysis, a decrease in $\mathrm{Hb}$ levels as little as $1 \mathrm{~g} / \mathrm{dL}$ was independently associated to a worsening of fatigue perception, after controlling by demographic and clinical characteristics, cancer and anemia treatments, and other biochemistry values. Thus, our results suggest that $1 \mathrm{~g} / \mathrm{dL}$ is a noteworthy change for the patient's point of view, at least in anemic patients. In a study with patients in palliative care, differences in fatigue were observed only between subgroups defined by a cutoff level of $10 \mathrm{~g} / \mathrm{dL}$, but not when the cutoff level was set to $12 \mathrm{~g} / \mathrm{dL}$ [33]. We noticed a similar degree of correlation between fatigue and absolute $\mathrm{Hb}$ levels at baseline and at 3 months, after anemia correction, which suggests that further benefits can be observed in patientreported fatigue at levels above $11 \mathrm{~g} / \mathrm{dl}$. A previous study of anemia correction with epoetin alfa reported that the greatest QoL increase was recorded when patients approached an $\mathrm{Hb}$ level of $12 \mathrm{~g} / \mathrm{dL}$, independent of the baseline Hb level [13].

Regarding the management of anemia in the study sample, it is similar than that described in previous studies [15], although we found a slightly higher use of iron supplementation than in 
the ECAS. Besides $\mathrm{Hb}$ level, other factors associated to fatigue in our cohort were the presence of advanced disease (as indicated by the significance of the variable "palliative cancer treatment intention"), chemotherapy administration, and a low Karnofsky index. The relationship found with transfusion need could be explained by the fact that transfusions have only transient effects, and have a limited capacity to ameliorate the symptoms of anemia $[34,35]$.

We found no significant relationship between fatigue and age, as previously described [36]. Gerber et al. [14], in a cohort of breast cancer patients, found that the biological characteristics associated with fatigue were high body mass index and white blood cell counts. Other studies in breast and liver cancer [37,38] and in patients with palliative care [33] found that fatigue was associated to psychological factors such as distress, depression, or anxiety (less prevalent in our sample). Through the results of the present and other recent studies, it is becoming evident that cancerrelated fatigue has several causal mechanisms [14]. For this reason, an individualised approach to its therapeutic management is needed [39-46].

The present study supports the potential usefulness of the brief PERFORM questionnaire for quickly assessing patient perception of fatigue in the clinical practice. A systematic review conducted in 2009 identified an extremely high number (up to 40) of validated instruments for measuring fatigue in cancer patients [47]. Only few of them were optimally tested for validity and reliability [48], and most tools were relatively insensitive to differences in fatigue to cancer stage. In addition, most instruments were too long to be administered in patients with advanced cancer. In the present study, the PERFORM questionnaire, which is almost as short as the nine-item Brief Fatigue Inventory, has demonstrated good sensitivity to change, and has the advantage over other tools that includes beliefs and attitudes of patients about fatigue. It is possible that this newly added dimension explains our findings about factors predicting fatigue not found in any previous study (i.e., transfusion need).

The main limitation of the study is the observational design, which does not allow the establishment of causal relationships. Treatment bias does not allow comparing outcomes in $\mathrm{Hb}$ or fatigue between subgroups defined by therapeutic management of anemia. Indirect associations between unmeasured variables and some of the described factors predicting fatigue might account for some of our findings, and thus results must be interpreted with caution.

\section{Conclusions}

Minimal increases or decreases in $\mathrm{Hb}$ of $\geq 1 \mathrm{~g} / \mathrm{dL}$ were associated with meaningful changes in patient-perceived fatigue as measured with the brief, 12-item PERFORM questionnaire. In addition to anemia severity, other factors such as active chemotherapy and advanced disease contribute to perceptions of fatigue by cancer patients. These results represent new evidence of the potential usefulness of PERFORM questionnaire for monitoring symptoms of fatigue in cancer patients.

Acknowledgments The study was conducted under the auspice of the Spanish Society of Medical Oncology. Writing assistance was supported by Amgen S.A. and provided by Dr. Neus Valveny from Trial Form Support. The authors wish to acknowledge Ariadna Lloansi (Amgen S.A.) for the critical review of the manuscript and Amgen SA for financial support of this study. The conclusions, interpretations, and opinions expressed herein are those of the authors.

PERFORM IV Study Group (in alphabetical order) Dr. Adolfo Frau Llopis, H. Provincial de Castellón; Dr. Adolfo Murias, Hosp. Insular de Gran Canaria; Dr. Alberto Arizcun, Compl. Hosp. de Palencia (Hosp. Río Carrión); Dr. Alberto Rodriguez, Hosp. Juan Ramón Jiménez; Dra. Almudena Martín, Hosp. Severo Ochoa; Dra. Amalia Velasco Ortiz, Hosp. La Princesa; Dr. Antonio González, Hosp. Ramón y Cajal; Dr. Antonio Sánchez, Dr. Mariano Provencio, Hosp. U. Puerta de Hierro; Dra. Belén Loboff, Dra. M. Luisa Gonzalvez, Hosp. Universitario Virgen de la Arrixaca; Dr. Brunet, Dra. Montse Velazco, ICO de Girona; Dr. Camps, Dra. Ana Blasco, Hosp. Gral. de Valencia; Dr. Carrato, Hosp. Gral. U. de Elche; Dr. César Rodríguez, Hosp. U. de Salamanca; Dra. Dolores Isla, Hosp. Lozano Blesa; Dra. Elena Filipovich, Dra. Juana $\mathrm{M}^{\mathrm{a}}$ Cano, Hosp. Ntra Sra. de Sonsoles; Dr. Francisco Ayala, Hosp. Morales Meseguer; Dra. Hae Jin SuhOh, Dr. Manuel Constenla, Hosp. de Pontevedra; Dr. Ignacio Duran, Hosp. de Madrid Norte Sanchinarro; Dr. J. L. Pérez Gracia, Clínica Univ. de Navarra; Dr. Javier Cassinello, Hosp. U. de Guadalajara ; Dr. Javier Castellanos, Dra. Lidia Vázquez, H. Xeral Cíes; Dr. Javier Puertas, Hosp. Río Hortega; Dr. Jesús García Mata, Compl. Hosp. Ourense (Hosp. Sta. María de Naí); Dra. Jiménez Orozco, Hosp. Gral. de Jerez ; Dr. Joan Carulla, Hosp. Mateu Orfila ; Dr. José Manuel Baena, Dr. Antonio Rueda, Hosp. Puerta del Mar; Dr. José Manuel Cuervo, Hosp. San Juan de Dios; Dr. José Ramón Mel, Hosp. Xeral Calde; Dr. Josep Manuel Piera, Hosp. Donostia; Dr. Juan Cueva Bañuelos, Hosp. Cl. Santiago de Compostela; Dr. Juan Ramón Delgado, Hosp. Virgen de las Nieves; Dr. Miguel Angel Cruz, Hosp. Virgen de la Salud; Dr. Miguel Mendez, Hosp. de Móstoles; Dra. Nieves Díaz, Hosp. San Juan de Alicante; Dr. Norberto Batista, Hosp. Univ. de Canarias La Laguna; Dr. Pedro López Tendero, Dra. Dolores Torregrosa, Dra. Regina Girones, Hosp. de Jativa/Xativa; Dr. Pedro Sánchez Rovira, Hosp. Gral. de Jaén; Dr. Pere Gascón, Hosp. Clínic i Provincial; Dra. Pilar García Alfonso, Hosp. Gregorio Marañón; Dr. Puerto Pica, Dr. Álvarez, Hosp. Infanta Cristina; Dra. Purificación Martínez del Prado, Hosp. de Basurto; Dr. Ramón Colomer, Centro MD Anderson; Dr. Ramón Pérez Carrión, Hosp. Quirón; Dra. Raquel Molina Villaverde, Hosp. Principe de Asturias; Dr. Roberto Fernández, Dr. Ignacio Peláez, Hosp. de Cabueñes; Dra. Ruth Vera, Hosp. de Navarra; Dr. Salvador Saura, Hosp. de Gran Canaria; Dr. Vicente Valentí, Hosp. Gral. de Catalunya; Dr. Vicente Valentin, Hosp. 12 de Octubre.

Authorship and disclosures J Carulla, J Cassinello, RC, JG, PG, CR and VV designed the study, coordinated the group, contributed to clinical data collection and reviewed the analysis and the manuscript. EB reviewed the analysis and the manuscript. All the authors approved the final version of the manuscript.

Eva Baró is employee of 3D Health Research. The authors declare no other conflict of interest relating to the publication of this manuscript. 
Open Access This article is distributed under the terms of the Creative Commons Attribution Noncommercial License which permits any noncommercial use, distribution, and reproduction in any medium, provided the original author(s) and the source are credited.

\section{Appendix}

Table 7 PERFORM questionnaire

\begin{tabular}{|c|c|c|c|c|c|}
\hline In the last 2 weeks, how frequent have you felt like these items? & Never & Sometimes & Often & Usually & Always \\
\hline 1. The slightest effort makes me very tired. & 1 & 2 & 3 & 4 & 5 \\
\hline 2. My tiredness (due to my illness or its treatment) has been very different to "normal" tiredness. & 1 & 2 & 3 & 4 & 5 \\
\hline 3. I've been tired the whole day long & 1 & 2 & 3 & 4 & 5 \\
\hline 4. I've spent the whole day sitting down because of my tiredness. & 1 & 2 & 3 & 4 & 5 \\
\hline 5. When I was tired, I've had to interrupt what I was doing and rest so as to be able to continue. & 1 & 2 & 3 & 4 & 5 \\
\hline 6. I've been very slow performing my usual activities. & 1 & 2 & 3 & 4 & 5 \\
\hline 7. I've needed help with tasks around the house because of my tiredness & 1 & 2 & 3 & 4 & 5 \\
\hline 8. I've felt bad about feeling tired at work. & 1 & 2 & 3 & 4 & 5 \\
\hline 9. In general, I believe my tiredness has made my life worse. & 1 & 2 & 3 & 4 & 5 \\
\hline 10. I've felt that I'm going downhill because of my tiredness. & 1 & 2 & 3 & 4 & 5 \\
\hline 11. I feel my tiredness has prevented me from living a normal life. & 1 & 2 & 3 & 4 & 5 \\
\hline 12. I've stopped doing things I liked doing because of my tiredness. & 1 & 2 & 3 & 4 & 5 \\
\hline
\end{tabular}

\section{References}

1. Mock V, Atkinson A, Barsevick A, Cella D, Cimprich B, Cleeland C, Donnelly J, Eisenberger MA, Escalante C, Hinds P, Jacobsen PB, Kaldor P, Knight SJ, Peterman A, Piper BF, Rugo H, Sabbatini $\mathrm{P}$, Stahl C (2000) NCCN practice guidelines for cancer-related fatigue. Oncology (Williston Park) 14:151-161

2. Diaz N, Menjon S, Rolfo C, Garcia-Alonso P, Carulla J, Magro A, Miramon J, Rodriguez CA, de Castellar R, Gasquet JA (2008) Patients' perception of cancer-related fatigue: results of a survey to assess the impact on their everyday life. Clin Transl Oncol 10:753-757

3. Barsevick A, Frost M, Zwinderman A, Hall P, Halyard M (2011) I'm so tired: biological and genetic mechanisms of cancer-related fatigue. Qual Life Res 19:1419-1427

4. Sprangers MA, Van Dam FS, Broersen J, Lodder L, Wever L, Visser MR, Oosterveld P, Smets EM (1999) Revealing response shift in longitudinal research on fatigue: the use of the thentest approach. Acta Oncol 38:709-718

5. Jacobsen PB, Hann DM, Azzarello LM, Horton J, Balducci L, Lyman GH (1999) Fatigue in women receiving adjuvant chemotherapy for breast cancer: characteristics, course, and correlates. J Pain Symptom Manag 18:233-242

6. Molassiotis A, Morris PJ (1999) Quality of life in patients with chronic myeloid leukemia after unrelated donor bone marrow transplantation. Cancer Nurs 22:340-349

7. Berger AM, Farr L (1999) The influence of daytime inactivity and nighttime restlessness on cancer-related fatigue. Oncol Nurs Forum 26(10):1663-1671

8. Romito F, Montanaro R, Corvasce C, Di Bisceglie M, Mattioli V (2008) Is cancer-related fatigue more strongly correlated to haematological or to psychological factors in cancer patients? Support Care Cancer 16:943-946
9. Yennurajalingam S, Palmer JL, Zhang T, Poulter V, Bruera E (2008) Association between fatigue and other cancer-related symptoms in patients with advanced cancer. Support Care Cancer $16: 1125-1130$

10. NCCN (2013) Cancer-related fatigue. NCCN Clinical practice guidelines in oncology. Version 1.2013. Available at: http://www.nccn.org/ professionals/physician_gls/pdf/fatigue.pdf. Accessed 21 Nov 2012

11. Gabrilove JL, Cleeland CS, Livingston RB, Sarokhan B, Winer E, Einhorn LH (2001) Clinical evaluation of once-weekly dosing of epoetin alfa in chemotherapy patients: improvements in hemoglobin and quality of life are similar to three-times-weekly dosing. J Clin Oncol 19:2875-2882

12. Patrick DL, Gagnon DD, Zagari MJ, Mathijs R, Sweetenham J (2003) Assessing the clinical significance of health-related quality of life (HrQOL) improvements in anaemic cancer patients receiving epoetin alfa. Eur J Cancer 39:335-345

13. Carteni G, Giannetta L, Ucci G, De Signoribus G, Vecchione A, Pinotti G, Puglisi F, Contillo A, Pezzella G, Orecchia S, Beccaglia P (2007) Correlation between variation in quality of life and change in hemoglobin level after treatment with epoetin alfa 40,000 IU administered once-weekly. Support Care Cancer 15:1057-1066

14. Gerber LH, Stout N, McGarvey C, Soballe P, Shieh CY, Diao G, Springer BA, Pfalzer LA (2011) Factors predicting clinically significant fatigue in women following treatment for primary breast cancer. Support Care Cancer 19:1581-1591

15. Ludwig H, Van Belle S, Barrett-Lee P, Birgegard G, Bokemeyer C, Gascon P, Kosmidis P, Krzakowski M, Nortier J, Olmi P, Schneider M, Schrijvers D (2004) The European Cancer Anaemia Survey (ECAS): a large, multinational, prospective survey defining the prevalence, incidence, and treatment of anaemia in cancer patients. Eur J Cancer 40:2293-2306

16. Canaparo R, Casale F, Muntoni E, Zara GP, Della Pepa C, Berno E, Pons N, Fornari G, Eandi M (2000) Plasma 
erythropoietin concentrations in patients receiving intensive platinum or nonplatinum chemotherapy. Br J Clin Pharmacol 50:146-153

17. Tas F, Eralp Y, Basaran M, Sakar B, Alici S, Argon A, Bulutlar G, Camlica H, Aydiner A, Topuz E (2002) Anemia in oncology practice: relation to diseases and their therapies. Am J Clin Oncol 25:371-379

18. Rajeswaran A, Trojan A, Burnand B, Giannelli M (2008) Efficacy and side effects of cisplatin- and carboplatin-based doublet chemotherapeutic regimens versus non-platinum-based doublet chemotherapeutic regimens as first line treatment of metastatic nonsmall cell lung carcinoma: a systematic review of randomized controlled trials. Lung Cancer 59:1-11

19. Demetri GD (2001) Anaemia and its functional consequences in cancer patients: current challenges in management and prospects for improving therapy. Br J Cancer 84(Suppl 1):31-37

20. Ludwig H (1999) Epoetin in cancer-related anaemia. Nephrol Dial Transplant 14(Suppl 2):85-92

21. Collado-Hidalgo A, Bower JE, Ganz PA, Cole SW, Irwin MR (2006) Inflammatory biomarkers for persistent fatigue in breast cancer survivors. Clin Cancer Res 12:2759-2766

22. Bower JE, Ganz PA, Aziz N, Fahey JL, Cole SW (2003) T-cell homeostasis in breast cancer survivors with persistent fatigue. $\mathrm{J}$ Natl Cancer Inst 95:1165-1168

23. Gripp S, Moeller S, Bolke E, Schmitt G, Matuschek C, Asgari S, Asgharzadeh F, Roth S, Budach W, Franz M, Willers R (2007) Survival prediction in terminally ill cancer patients by clinical estimates, laboratory tests, and self-rated anxiety and depression. J Clin Oncol 25:3313-3320

24. Bower JE, Ganz PA, Aziz N (2005) Altered cortisol response to psychologic stress in breast cancer survivors with persistent fatigue. Psychosom Med 67:277-280

25. Bower JE, Ganz PA, Aziz N, Olmstead R, Irwin MR, Cole SW (2007) Inflammatory responses to psychological stress in fatigued breast cancer survivors: relationship to glucocorticoids. Brain Behav Immun 21:251-258

26. Ancoli-Israel S, Moore PJ, Jones V (2001) The relationship between fatigue and sleep in cancer patients: a review. Eur J Cancer Care (Engl) 10:245-255

27. Berger AM, Farr LA, Kuhn BR, Fischer P, Agrawal S (2007) Values of sleep/wake, activity/rest, circadian rhythms, and fatigue prior to adjuvant breast cancer chemotherapy. J Pain Symptom Manag 33:398-409

28. Roscoe JA, Kaufman ME, Matteson-Rusby SE, Palesh OG, Ryan JL, Kohli S, Perlis ML, Morrow GR (2007) Cancer-related fatigue and sleep disorders. Oncologist 12(Suppl 1):35-42

29. Baro E, Carulla J, Cassinello J, Colomer R, Mata JG, Gascon P, Gasquet JA, Rodriguez CA, Valentin V (2011) Psychometric properties of the Perform Questionnaire: a brief scale for assessing patient perceptions of fatigue in cancer. Support Care Cancer 19:657-666

30. Baro E, Carulla J, Cassinello J, Colomer R, Mata JG, Gascon P, Gasquet JA, Herdman M, Rodriguez CA, Sanchez J, Valentin V (2009) Development of a new questionnaire to assess patient perceptions of cancer-related fatigue: item generation and item reduction. Value Health 12:130-138
31. Baro E, Herdman M, Gasquet J, Sánchez J (2004) Instruments to measure patient-reported outcomes and perceptions of cancerrelated fatigue: a review of the literature. Value Health 7:PCN32

32. Demetri GD, Kris M, Wade J, Degos L, Cella D (1998) Quality-oflife benefit in chemotherapy patients treated with epoetin alfa is independent of disease response or tumor type: results from a prospective community oncology study. Procrit Study Group. J Clin Oncol 16:3412-3425

33. Munch TN, Zhang T, Willey J, Palmer JL, Bruera E (2005) The association between anemia and fatigue in patients with advanced cancer receiving palliative care. J Palliat Med 8:1144-1149

34. Ludwig H (2002) Anemia of hematologic malignancies: what are the treatment options? Semin Oncol 29:45-54

35. Osterborg A (1998) Recombinant human erythropoietin (rHuEPO) therapy in patients with cancer-related anaemia: what have we learned? Med Oncol 15(Suppl 1):S47-S49

36. Aapro MS, Cella D, Zagari M (2002) Age, anemia, and fatigue. Semin Oncol 29:55-59

37. Haghighat S, Akbari ME, Holakouei K, Rahimi A, Montazeri A (2003) Factors predicting fatigue in breast cancer patients. Support Care Cancer 11:533-538

38. Shun SC, Lai YH, Jing TT, Jeng C, Lee FY, Hu LS, Cheng SY (2005) Fatigue patterns and correlates in male liver cancer patients receiving transcatheter hepatic arterial chemoembolization. Support Care Cancer 13:311-317

39. Mitchell SA (2010) Cancer-related fatigue: state of the science. PM R 2:364-383

40. Jacobsen PB, Donovan KA, Vadaparampil ST, Small BJ (2007) Systematic review and meta-analysis of psychological and activitybased interventions for cancer-related fatigue. Health Psychol 26:660-667

41. Luctkar-Flude MF, Groll DL, Tranmer JE, Woodend K (2007) Fatigue and physical activity in older adults with cancer: a systematic review of the literature. Cancer Nurs 30:E35-E45

42. Revicki DA, Stull D, Vernon M, Rader M, Tomita D, Viswanathan HN (2012) Assessing the effect of darbepoetin alfa on patientreported fatigue in chemotherapy-induced anemia in four randomized, placebo-controlled clinical trials. Qual Life Res 21:311-321

43. Glaspy J (2001) Anemia and fatigue in cancer patients. Cancer 92:1719-1724

44. Esquerdo G, Llorca C, Cervera JM, Orts D, Juarez A, Carrato A (2011) Effectiveness of darbepoetin alfa in a cohort of oncology patients with chemotherapy-induced anaemia. Relationship between variation in three fatigue-specific quality of life questionnaire scores and change in haemoglobin level Clin Transl Oncol 13:341-347

45. Calabrich A, Katz A (2011) Management of anemia in cancer patients. Future Oncol 7:507-517

46. De Waele S, Van Belle S (2010) Cancer-related fatigue. Acta Clin Belg 65:378-385

47. Seyidova-Khoshknabi D, Davis MP, Walsh D (2011) Review article: a systematic review of cancer-related fatigue measurement questionnaires. Am J Hosp Palliat Care 28:119-129

48. Agasi-Idenburg C, Velthuis M, Wittink H (2010) Quality criteria and user-friendliness in self-reported questionnaires on cancerrelated fatigue: a review. J Clin Epidemiol 63:705-711 